Mitchell, P. \& Moyle, J. (1959). J. gen. Microbiol. 20, 434-441

\title{
Permeability of the Envelopes of Staphylococcus aureus to some Salts, Amino Acids, and Non-Electrolytes
}

\author{
By P. MITCHELL AND JENNIFER MOYLE \\ Zoology Department, University of Edinburgh
}

SUMMARY: The passive permeability properties of the plasma-membrane of Staphylococcus aureus (strain Duncan) resemble those of a classical lipid membrane such as that considered by Overton in 1899. In general, solutes carrying more than four water molecules flow across the plasma-membrane only very slowly under an electrochemical gradient. The plasma-membrane is the effective osmotic barrier to small molecular weight solutes and prevents the escape of internal components having a total osmotic concentration corresponding to $c$. 1 molal sucrose. The protoplast is prevented from swelling by the cell wall which withstands a hydrostatic thrust of some 20 to 30 atmospheres pressure exerted against it by the plasmamembrane in distilled water. The pores in the cell wall, although large enough to permit rapid diffusion of small molecular weight solutes, are too small to allow a dextran of mol. wt. 10,000 to penetrate. The cell wall acts as the osmotic barrier for large molecular weight components, preventing such components in the medium from gaining access to the plasma-membrane surface and preventing such internal components from passing outwards from the surface of the plasma-membrane.

In this paper we have collected together observations made at intervals during the last four years on the permeability of the envelopes of Staphylococcus aureus (strain Duncan). Part of this work was done in the Biochemistry Department, University of Cambridge.

'Permeability.' The word permeability as used in this paper is an index of the rate at which a given solute undergoes net transport through the plasmamembrane under an electrochemical gradient. For reasons which have been discussed elsewhere (Mitchell \& Moyle, 1956b), permeability in this sense must not be confused with the property of a membrane which may allow exchange of a solute across it without net transport. However, while we wish to restrict the meaning of permeability here to the description of net transport, we do not wish to restrict it to the sense given by the permeability coefficient as defined by a law of the Fick type, because we do not know whether the rates of solute diffusion which we describe in this paper are linear functions of the concentration or electrochemical gradient as they would have to be if they were described by a Fick law.

Plasma-membrane. The word plasma-membrane is used to describe the outer region of the protoplasm of the bacterium which is normally in contact with the inner surface of the cell wall. This region consists of a lipo-protein sheet, c. $5 \mathrm{~m} \mu$ thick containing some $20 \%$ lipid and $\mathbf{4 0} \%$ protein (Mitchell \& Moyle, 1951). Comparison of the phosphate-impermeable volume of Staphylococcus aureus with the volume of the protoplast calculated from the geometry of close-packed suspensions of the cocci indicates that the osmotic barrier for 
phosphate is some part of the plasma-membrane (Mitchell, 1953). Similar considerations, applied to intact organisms and to protoplasts freed from the mechanical protection of the cell wall, imply that the osmotic barrier for small molecular weight solutes is some part of the plasma-membrane in Bacillus megaterium (Weibull, 1955), Micrococcus lysodeikticus and Sarcina lutea (Mitchell \& Moyle, 1956a,c), and several strains of Staphylococcus aureus and albus (Mitchell \& Moyle, 1957).

In the present paper we shall describe the plasma-membrane of Staphylococcus aureus by its functions (i) of retaining internal solutes, and (ii) of excluding external solutes. Function (i) may be assessed from the internal osmotic pressure measured either by the osmotic pressure required to prevent swelling and lysis of cell-wall-free protoplasts, as already described (Mitchell $\&$ Moyle, $1956 c, 1957)$; or by a vapour pressure equilibrium method applicable to intact organisms (Mitchell \& Moyle, 1956 $a$ ) which we shall now describe in full. Function (ii) may be assessed by measurements of the rate of penetration of solutes into the cells of very thick suspensions of organisms, or by measurements of the rate of swelling and lysis of protoplasts suspended in isotonic or hypertonic solutions of the solute to be studied.

\section{METHODS}

Growth and preparation of organisms. Staphylococcus aureus (strain Duncan) was grown, harvested and washed as previously described by Mitchell (1953) and by Mitchell \& Moyle (1957).

Osmotic pressure measurements by vapour pressure equilibrium. A washed suspension of Staphylococcus aureus, harvested near the stationary phase of growth (2 mg. dry weight/ml.), containing $c .1 \mathrm{~g}$. dry-weight organisms was centrifugally concentrated to give a just pipettable suspension of some $250 \mathrm{mg}$. dry weight $/ \mathrm{ml}$. Samples $(\mathbf{0 \cdot 2} \mathrm{ml}$.) of this suspension were carefully but rapidly extruded (taking $c .60 \mathrm{sec}$.) from a $0.2 \mathrm{ml}$. pipette on to the centre of pieces of polythene $4 \mathrm{~cm}$. square so as to form circular films $1.5 \mathrm{~cm}$. in diameter, and each was immediately covered by a watch-glass to prevent evaporation. The cell samples were then weighed to within the nearest $0.1 \mathrm{mg}$. and were transferred to small desiccators, each containing a dish of aqueous sucrose solution (10 ml.) of known molality, close to the surface of which $(c .2 \mathrm{~mm}$.) the polythene squares could be placed with the film of organisms downwards. The desiccators were simultaneously evacuated to a pressure of $2 \mathrm{~mm}$., measured by a McLeod gauge, and vapour equilibration was allowed to proceed at $20^{\circ}$. In order to prevent air bubbles from splashing droplets of the sucrose solutions on to the polythene films, it was found to be necessary to de-gas the sucrose solutions by a preliminary period of evacuation. It was found that vapour equilibrium was practically complete in $5 \mathrm{hr}$. under the conditions of these experiments, and the films of organisms were accordingly reweighed after $5 \mathrm{hr}$. of equilibration. A longer period of equilibration was not desirable as it was important to minimize lysis and other changes which might occur to the organisms. The dry weight at zero vapour pressure was found by 
equilibrating films over phosphorus pentoxide in vacuo. From these observations the weight of water retained/unit weight organisms could be related to the equilibrium water vapour pressure of equivalent osmotic pressure.

Permeability measurements on thick suspensions. The basic methods used in handling the suspensions were as previously described (Mitchell, 1953). The permeability measurements with glutamate, glutamine, glycine, and a Leuconostoc dextran of mol. wt. 10,000 were done at $\mathrm{pH} 7$ in $0.1 \mathrm{M}-\mathrm{NaCl}$ and $0.01 \mathrm{M}-$ sodium phosphates. Glutamic acid and glutamine were measured by the decarboxylase method (Gale, 1945), and glycine was measured by oxidation with triketohydrindene hydrate, distillation of the formaldehyde produced and colorimetric estimation with chromotropic acid (Alexander, Landwehr \& Seligman, 1945). The dextran was measured by the anthrone reaction as described by Mitchell \& Moyle (1951).

The permeability measurements on chloride and thiocyanate were done with an initial concentration of $0.1 \mathrm{M}$-sodium salts in the presence of $0.01 \mathrm{M}$ sodium phosphates at $\mathrm{pH} \mathbf{7 \cdot 2}$. Chloride and thiocyanate were estimated volumetrically by adding excess silver nitrate and back-titrating with thiocyanate in dilute nitric acid, with ferrous ammonium sulphate as indicator. The volume of the cells impermeable to phosphate was determined at the same time as the volume impermeable to the other solutes, as a check on the variations in cell size that were found to occur from one culture to another.

Permeability measurements by 'protoplast' lysis. The protoplasts were released from the mechanical protection of the cell wall, and the extent of lysis of the 'protoplast' suspensions was measured by light extinction as previously described (Mitchell \& Moyle, 1957). The permeability measurements were done at $20^{\circ}$ in 1.5 molal solutions containing $0.01 \mathrm{M}$-sodium phosphates at $\mathrm{pH} 6.8$.

\section{RESULTS AND CONCLUSIONS}

Figure 1 shows the results of the vapour pressure equilibrium measurements, plotted as the weight of water/g. dry weight organisms against the reciprocal of the molality of the equilibrating sucrose solutions. Since the behaviour of sucrose solutions is nearly ideal, it can be taken that the reciprocal of the molality of the equilibrating sucrose solution is proportional to the reciprocal of the difference between the equivalent osmotic pressure and the hydrostatic pressure of the cytoplasm of the cells at equilibrium. In an ideal solution (in which the solute molecules move independently of each other and of the molecules of solvent) the reciprocal of the osmotic pressure is proportional to the weight (or volume) of solvent. It will be seen in Fig. 1 that the weight of water held in the organisms was proportional to the reciprocal of the osmotic pressure (or to $1 /$ molality of sucrose) for values up to $1.8 \mathrm{~g}$. water/g. dry weight organisms, corresponding to an osmotic pressure of 1 molal sucrose. But, above this value, the weight of water held by the organisms increased much more slowly with the reciprocal of the osmotic pressure of the equilibrating sucrose solutions. The weight of water held by the organisms at the 
upper limit of the linear range of the graph (1.8 g. water/g. dry weight organisms) was in reasonably good agreement with the volume of water in the protoplasts estimated directly to be 1.5-1.6 ml./g. dry-weight organisms (Mitchell, 1953). Probably the additional $0 \cdot 2-0 \cdot 3 \mathrm{~g}$. water found by the vapour-pressure equilibrium measurements was held by hydrophilic components of the cell wall. The position of the discontinuity in the graph implies that the cell wall resisted the dilution of the solutes contained within the protoplast beyond a content of $1.8 \mathrm{~g}$. water/g. dry weight organisms. As the equilibrating vapour pressure (or 1 /molality of sucrose) was raised above this point, the elasticity of the cell wall would be taken up and the internal osmotic pressure, exerted

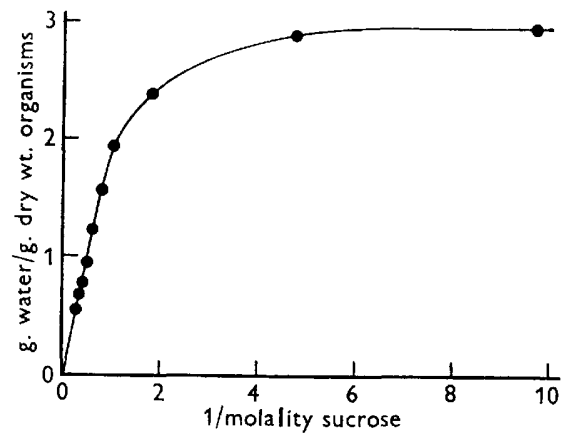

Fig. 1

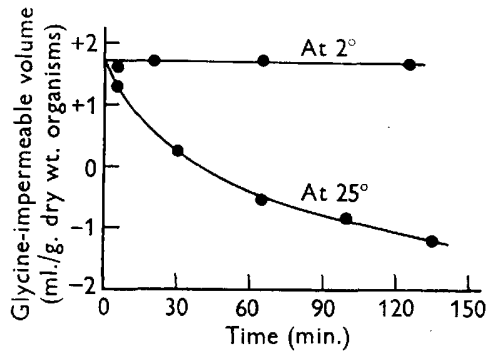

Fig. 2

Fig. 1. Vapour pressure equilibrium data for Staphylococcus aureus (strain Duncan), given as g. water retained/g. dry wt. organisms in equilibrium with sucrose solutions of known molality at $20^{\circ}$.

Fig. 2. Time course of glycine-impermeable volume of Staphylococcus aureus (strain Duncan) at $2^{\circ}$ and $25^{\circ}$.

against the plasma-membrane, would be compensated by the hydrostatic pressure of the cell wall, so that the equilibrium vapour pressure would correspond to that of the water outside the organisms. This water would contain a little solute due, presumably, to a small degree of cell lysis or leakage. We may conclude that the normal osmotic pressure of the cytoplasm of these organisms corresponded approximately to 1 molal sucrose or to some 20 to 25 atmospheres, in good agreement with the value obtained by measurements of the dependence of the swelling and lysis of the 'protoplasts' of this organism on the tonicity of the suspension media (Mitchell \& Moyle, 1957).

Table 1 shows the volume of Staphylococcus aureus impermeable to glutamic acid, glutamine, glycine, chloride, thiocyanate and a Leuconostoc dextran (mol.wt.10,000) at ionic strength $0 \cdot 1$ and close to neutrality. The corresponding phosphate-impermeable volumes are also given for comparison since, as will be seen, the volume of the organisms varied somewhat from one batch to another. The values in brackets were obtained after treating the organisms with $5 \%(w / v)$ $n$-butanol in water for $10 \mathrm{~min}$. at $2^{\circ}$. The last column shows the amount of the solutes which appeared to pass in through the osmotic barrier, assuming the position of this barrier to be given by the phosphate-impermeable 

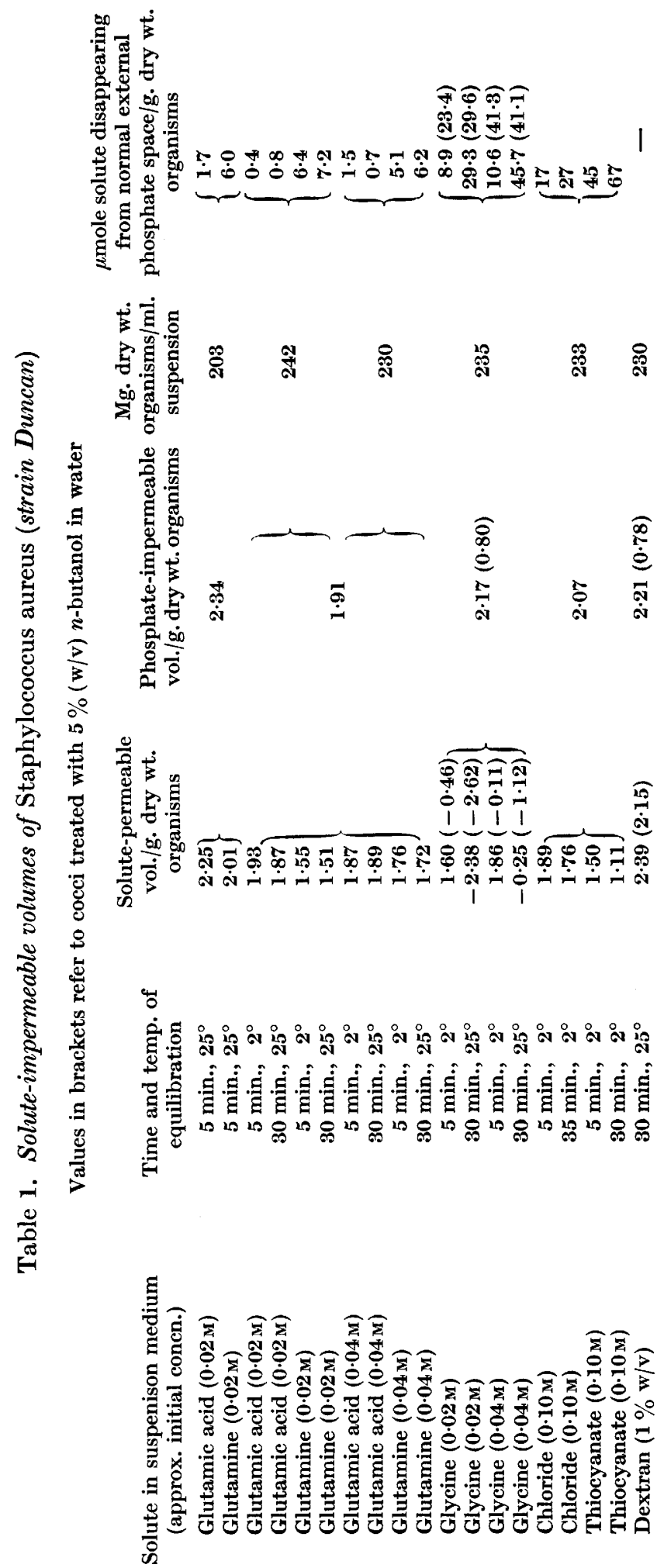
volumes: the figures may represent either permeation or adsorption. It will be observed that neither glutamic acid nor glutamine penetrated the osmotic barrier to a significant extent during $30 \mathrm{~min}$. at $25^{\circ}$, but, whereas glutamic acid behaved almost exactly like inorganic phosphate, some 5-7 $\mu$ mole glutamine disappeared from the external phosphate space within $5 \mathrm{~min}$. (the time required for centrifugation) at $2^{\circ}$. Since the amount of glutamine which disappeared was approximately the same whether the external concentration was 0.02 or $0.04 \mathrm{M}$, and the amount increased very little in 5 or $30 \mathrm{~min}$. at $\mathbf{2 5}^{\circ}$, it seems probable that this glutamine was adsorbed on the cell wall or on the surface of the osmotic barrier. The value for the glycine-impermeable volume is similar to that for glutamine at $2^{\circ}$, but at $25^{\circ}$ it rapidly becomes negative. This means that the amount of glycine which disappeared from the suspension medium was greater than can be accounted for by completely uniform distribution even including the space that must be occupied by the substance of the organisms. The organisms therefore appeared to occupy a negative volume. On adding butanol to give a $5 \%$ solution so as to break the osmotic barrier of the cells, an amount of glycine was taken up from the medium which was near to that taken up by intact organisms in $30 \mathrm{~min}$. at $25^{\circ}$, even in the suspensions held at $2^{\circ}$ (values in brackets, Table 1 ). The results indicate that at $2^{\circ}$ the organisms were impermeable to glycine, but that some $10 \mu$ mole glycine was adsorbed outside the osmotic barrier. When the organisms were treated with butanol or when the temperature was raised to $25^{\circ}$ the glycine evidently passed through the osmotic barrier. Since the cell materials must occupy some $0.8 \mathrm{ml}$./g. dry weight organisms, the total amounts of glycine which disappeared when the osmotic barrier was broken with butanol at $2^{\circ}$ were 15 and $24 \mu \mathrm{mole} / \mathrm{g}$. dry weight organisms when the final glycine concentrations were, respectively, 8 and $18 \mathrm{~mm}$. It is unlikely that this glycine was metabolized at $2^{\circ}$ in the presence of $5 \%$ butanol, and hence it was probably adsorbed, partly in the surface (where it adsorbs before penetration) and partly within the cells. This is in accord with Gale's observation of a spontaneous uptake of radioactive glycine by this organism (Gale, 1953). In order to throw more light on the relative rates of permeation of glycine at $2^{\circ}$ and at $\mathbf{2 5}^{\circ}$, the time course of the glycine-impermeable volume was measured, with an initial glycine concentration of $0.04 \mathrm{M}$ (Fig. 2). At $2^{\circ}$, glycine did not permeate significantly in $2 \mathrm{hr}$., but at $25^{\circ}$ half-equilibration occurred in c. $30 \mathrm{~min}$. The fact that glycine permeation has a very high temperature coefficient suggests that it may involve a specific carrier mechanism.

Judging from the values in Table 1, chloride entered the cells slowly, and thiocyanate entered rapidly at $2^{\circ}$. The chloride- and thiocyanate-impermeable volumes are plotted against time at $2^{\circ}$ in Fig. 3, with phosphate for comparison. It appears as though Staphylococcus aureus is somewhat permeable to chloride, and very permeable to thiocyanate. The thiocyanate ion does not seriously damage the osmotic barrier at this concentration, for even $\mathrm{M}-\mathrm{NaCNS}$ was found not to cause leakage of phosphate across the osmotic barrier. Since the anion and cation probably penetrate independently, these results suggest that $\mathrm{Na}^{+}$penetrates readily while the ease of penetration for the anions is in 
the order $\mathrm{CNS}^{\prime}>\mathrm{Cl}^{\prime}>\left(\mathrm{H}_{2} \mathrm{PO}_{4}{ }^{\prime}+\mathrm{HPO}_{4}{ }^{\prime \prime}\right)$. We cannot, however, exclude the possibility that thiocyanate artificially raises the permeability of the plasmamembrane to $\mathrm{Na}^{+}$. The fact that the equilibration of $\mathrm{Cl}^{\prime}$ appeared to become complete when only some $\mathbf{0 . 5} \mathrm{ml}$. of the total protoplasmic water $(c .1 .2 \mathrm{ml} . / \mathrm{g}$. dry weight organisms in this experiment) would have become accessible, suggests that either the chloride ion was exchanging stoichiometrically across the membrane for some other anion, or that the coccal suspension was not homogeneous and only some $40 \%$ of the cocci were permeable to chloride.

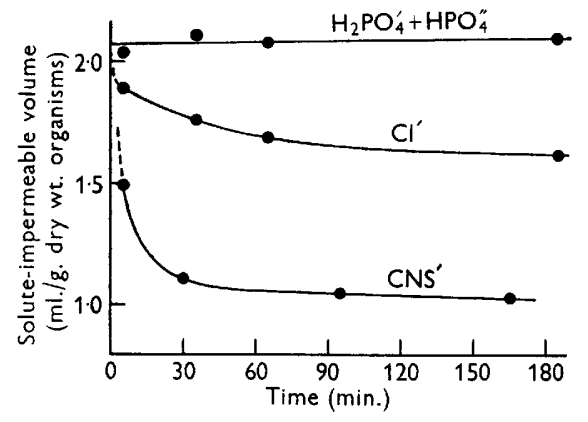

Fig. 3

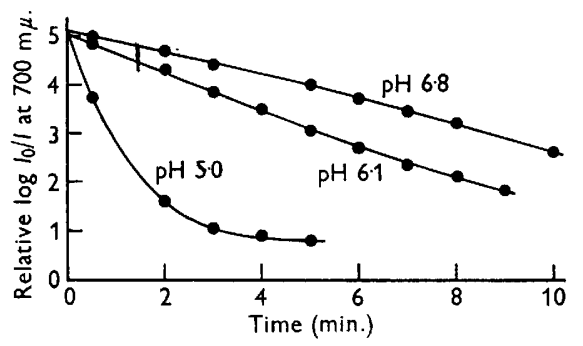

Fig. 4

Fig. 3. Time-course of phosphate-, chloride-, and thiocyanate-impermeable volumes of Staphylococcus aureus (strain Duncan) at $2^{\circ}$.

Fig. 4. Time-course of permeation of KCNS into 'protoplasts' of Staphylococcus aureus (strain Duncan) at three $\mathrm{pH}$ values. 'Protoplasts' suspended in 1.5 molal KCNS

Table 1 shows that the volumes impermeable to phosphate and to dextran in normal cocci were, respectively, $2 \cdot 21$ and $2 \cdot 39 \mathrm{ml}$./g. dry weight organisms, while after treatment with butanol they were 0.78 and $2 \cdot 15 \mathrm{ml} . / \mathrm{g}$. dry weight organisms. Thus, the osmotic barrier for phosphate is not the same as that for the relatively high molecular weight $(\mathbf{1 0 , 0 0 0 )}$ dextran. The osmotic barrier for phosphate must be part of the plasma-membrane, while the osmotic barrier for the dextran (approaching from outside) is presumably the outer region of the cell wall.

The rate of lysis of the 'protoplasts' of Staphylococcus aureus is less than $10 \% / \mathrm{hr}$. at $20^{\circ}$ in 1.5 molal solutions of the following solutes at $\mathrm{pH} 6.8$ in the presence of $0.01 \mathrm{~m}$-sodium phosphates, except where otherwise indicated: $\mathrm{NaCl}, \mathrm{KCl}, \mathrm{NH}_{4} \mathrm{Cl}, \mathrm{KBr}, \mathrm{KNO}_{3}$, sodium acetate ( $\mathrm{pH} 9$ ), potassium acetate (pH 9), $\mathrm{K}_{2} \mathrm{SO}_{4},\left(\mathrm{KH}_{2} \mathrm{PO}_{4}+\mathrm{K}_{2} \mathrm{HPO}_{4}\right)$, sodium glutamate, lysine hydrochloride, D-glucose, D-sorbose, D-mannose, D-galactose, D-fructose and sucrose. In KCNS, however, the 'protoplasts' break in the course of a few minutes as shown in Fig. 4, the rate of breakage being very sensitive to the $\mathrm{pH}$ value. In NaCNS, similar curves show a rate of lysis $c .0 \cdot 8$ of that observed in the corresponding KCNS solution. The more rapid lysis at lower $\mathrm{pH}$ values could not be due simply to an increase in the fragility of the 'protoplasts', for there was no lysis in $\mathrm{NaCl}$ solutions at corresponding $\mathrm{pH}$ values. These results are in accord with the observations described above on the permeability of intact 
$S$. aureus to thiocyanate. The time for half-lysis of the 'protoplasts' of $S$. aureus is less than 3 sec. for glycerol, it is 20 sec. for erythritol, 5 min. for D-ribose, $30 \mathrm{~min}$. for L-arabinose and $20 \mathrm{~min}$. for D-sorbitol. The 'protoplasts' lyse almost instantaneously in 1.5 molal urea or glycine, but it is probable that these protein denaturants have a direct effect upon the fragility of the membrane.

It is evident that the permeability properties of the cells of Staphylococcus aureus freed from the mechanical protection of the cell wall are essentially similar to those of Micrococcus lysodeikticus and Sarcina lutea, and closely resemble those of intact $S$. aureus. The plasma-membranes of these organisms appear to exhibit the passive permeability properties expected of a classical lipid membrane like that originally considered by Overton in 1899.

We would like to acknowledge the receipt of personal grants from the Scottish Hospital Endowments Research Trust in aid of this work. We are also indebted to the Rockefeller Foundation for a grant for equipment.

\section{REFERENCES}

Alexander, B., Landwehr, G. \& Seligman, A. M. (1945). A specific micromethod for the colorimetric determination of glycine in blood and urine. J. biol. Chem. $160,51$.

GaLE, E. F. (1945). Studies on bacterial amino-acid decarboxylases. 5. The use of specific decarboxylase preparations in the estimation of amino-acids and in protein analysis. Biochem. $J .39,46$.

GaLE, E. F. (1953). Assimilation of amino-acids by Gram-positive bacteria and some actions of antibiotics thereon. Advanc. Protein Chem. 8, 285.

Mrrchell, P. (1953). Transport of phosphate across the surface of Micrococcus pyogenes: nature of the cell 'inorganic phosphate'. J. gen. Microbiol. 9, 273.

Mitcheld, P. \& MoyLe, J. (1951). The glycerophosphoprotein complex envelope of Micrococcus pyogenes. J. gen. Microbiol. 5, 981.

Mrtchell, P. \& Moyle, J. (1956a). Osmotic function and structure in bacteria. In Bacterial Anatomy. Symp. Soc. gen. Microbiol. 6, 150.

Mitcheld, P. \& Moyle, J. (1956 b). Permeation mechanisms in bacterial membranes. Disc. Faraday Soc. 21, 258.

Mrtchell, P. \& Moyle, J. (1956c). Liberation and osmotic properties of the protoplasts of Micrococcus lysodeikticus and Sarcina lutea. J. gen. Microbiol. 15, 512.

Mitchell, P. \& Moyle, J. (1957). Autolytic release and osmotic properties of 'protoplasts' from Staphylococcus aureus. J. gen. Microbiol. 16, 184.

Overton, E. (1899). Über die allgemeinen osmotischen Eigenschaften der Zellen, ihre vermutlichen Ursachen und ihre Bedeutung für die Physiologie. Vjschr. naturf. Ges. Zürich, 44, 88.

WeIBull, C. (1955). The localization of a permeability barrier in the cells of Bacillus megaterium. Exp. Cell Res. 9, 139. 